in vivo $34: 2193-2199(2020)$

doi:10.21873/invivo.12029

Review

\title{
Cutaneous Stomal Recurrence of Colorectal Cancer After Curative Rectal Cancer Surgery - A Case Report and Systematic Review
}

\author{
SIMON DAVEY and KATHRYN MCCARTHY \\ Department of Colorectal Surgery, North Bristol NHS Trust, Bristol, U.K.
}

\begin{abstract}
Background/Aim: Stomal metastases from a primary rectal adenocarcinoma are rare, therefore, clear guidelines on treatment options are limited. We performed a systematic review including a case report on this subject with the primary objective of identifying the total number of cases in the literature. The secondary objective was to assess median survival. Materials and Methods: A 59-year-old woman presented to our institution with anal incontinence to mucus leakage. Flexible sigmoidoscopy identified a carpet adenoma from the dentate line to the rectosigmoid junction. An abdomino-perineal resection (APR) was performed using the transanal total mesorectal excision technique (TaTME). No adjuvant chemotherapy was offered. Twenty-one months following the operation a stomal recurrence was identified. Palliative radiotherapy was commenced and the patient is alive 6 months later with no visible recurrence at the site of the stoma. A systematic review was performed in accordance with the Preferred Reporting Items for Systematic Review and Meta-Analysis (PRISMA) guidelines. Results: The systematic review identified 19 individual cases of either metachronous or true metastatic recurrence, including our own case. Median survival was 30 months in the 8 cases where further treatment was offered and accepted. Conclusion: Stomal metastases or metachronous colorectal cancer is uncommon. The causes for this pattern of spread are not clear. Long-term survival from cutaneous recurrence is generally poor. For carefully selected patients, redo surgery is an option with satisfactory results.
\end{abstract}

This article is freely accessible online.

Correspondence to: Simon Davey, North Bristol NHS Trust, Southmead Road, Bristol, BS10 5NB, UK. Tel: +44 07715171637 , e-mail:drsdavey@gmail.com

Key Words: Rectal adenocarcinoma, TaTME, stomal recurrence.
An estimated 704,000 new cases of rectal cancer were diagnosed worldwide in 2018 according to GLOBOCAN data, making it the eighth most common cancer of all cancers diagnosed globally (1). Low rectal cancers, defined as those "with its lower edge at, or below, the origin of the levators on the pelvic sidewall" (2) should be considered for an abdominoperineal resection (APR), taking either an intersphincteric approach or, for more advanced tumours, using the extra-levator "ELAPE" technique (2). Although the incidence of APR has fallen in recent years as the use of the laparoscopic low anterior resection (LAR) has increased, it still accounts for about $25 \%$ of operations of rectal cancer (3). Local recurrence rates with APR are as high as $33 \%$ as opposed to $13 \%$ with LAR (4) and five-year survival rates are in the region of $38-60 \%$ and $57-76 \%$ respectively (4). Proven recurrence at a wound site is rare and sparsely reported in the literature, but an estimate of approximately $4 \%$ recurrence has been documented in low rectal cancer (5). There are very few cases in the literature. The latest technique employed to resect rectal cancers is the transanal total mesorectal excision (TaTME). This involves two surgical teams operating from the abdomen and anus with gas insufflation at both ends. The abdominal dissection takes place as for a standard laparoscopic anterior resection. The surgeon operating from the anus creates a rectotomy below the tumour and meets the abdominal surgeon's resection as the dissection continues cranially, critically outside the mesorectal fascia. A full description of this novel technique is given by Arroyave et al. (6).

We have undertaken a systematic review, which includes our own case report written up below, to identify how many cases of either true metastatic disease or metachronous recurrence have been reported at a stoma site, where the original stoma was created as part of a primary resection for rectal cancer with curative intent. The possible reasons for recurrence and treatment options are discussed. This systematic review was undertaken in response to having had 
a proven stomal metastatic deposit at the site of a colostomy following trans-anal rectal surgery in our institution in 2019. Our case involves a 59 year old female who presented with incontinence to anal mucus leakage. The cause was identified as a large carpet adenoma within which an adenocarcinoma was identified, from the dentate line to the rectosigmoid junction. An intersphnicteric APR was undertaken. 21 months following that operation, a stomal recurrence was identified. Palliative radiotherapy was commenced and the patient is still alive 6 months later.

\section{Materials and Methods}

A systematic review of the literature was performed in accordance with the Preferred Reporting Items for Systematic Review and MetaAnalysis (PRISMA) guidelines. PubMed, Embase (since 1980), Medline, Google Scholar, CENTRAL, CINNAHL and The Cochrane Library were searched using the following MeSH search terms "peristomal recurrence", "peristomal metastasis", "stomal recurrence", "stomal metastasis", "rectal cancer", "colon cancer", "colonic cancer", "colorectal cancer", "rectal adenocarcinoma", "colon adenocarcinoma", "colonic adenocarcinoma", "colostomy recurrence", "colostomy metastasis", "colostomy site recurrence", "colostomy site metastasis"; terms were combined using "and/or" as appropriate with pluralisation also used where indicated (metastasis/metastases). Variations in hyphenation were also included. Bibliographies of relevant papers were used to identify additional studies or reports. Our own case report was added to the data. The most recent search was conducted on the $3^{\text {rd }}$ of February, 2020. Data points extracted for analysis within the systematic review included: i) the location of cancer, ii) age at initial presentation, iii) type of operation originally undertaken, iv) sex of patient, v) interval between initial operation and stomal recurrence, vi) original histology, vii) overall survival and viii) treatment offered for the recurrence. The data was recorded within a simple spreadsheet (Microsoft Excel), which enabled direct assessment and comparison between the identified cases. Median survival was calculated using the standard formulas within Microsoft Excel. The extracted data points are presented in Tables I and II.

Inclusion criteria. Given the scarcity of these cases, all published articles, case reports, letters and conference abstracts were considered for inclusion where recurrence of a rectal or colonic cancer at the stoma site was mentioned.

Exclusion criteria. Papers published in languages other than English where a translation was not available were excluded.

Outcome measures. The primary outcome from this systematic review was to collate the number of cases reported worldwide to gain insight into how common a problem or not this pattern of spread has become. The secondary outcome was to report the median survival of the identified cases, once a metastatic deposit had been found. In addition, we were interested to report how common metachronous recurrences are, and suggest guidance on how to best treat this rare entity.

Study selection. The primary author (SRD) performed the search, undertaking a title screen followed by an abstract review, and then a full-text review of potentially eligible papers. Where doubt existed as to the relevance of a paper, this was escalated to the senior author for review (KMC). Publications without abstracts directly underwent full text review, if available.

Quality assessment. There was no formal assessment of the quality of the articles considered, since almost all were either case reports or limited case series, thus, applying quality assessment criteria, such as MINORs, was not applicable. No randomised control trials were identified from the search.

\section{Case Report}

Our case involves a 59-year-old lady presenting with anal incontinence to mucus leakage, from whom written consent was obtained, permitting the authors to include her case in this systematic review. She had no abdominal symptoms and no family history of gastrointestinal disorders. Flexible sigmoidoscopy revealed a large, circumferential carpet adenoma extending from the dentate line to the rectosigmoid junction. Biopsies of the polyp were villous adenoma with low grade dysplasia. It was agreed with the patient and at the colorectal multi-disciplinary team (MDT) meeting that an intersphincteric APR was the best surgical option as a piecemeal endoscopic excision conferred a high risk of polyp recurrence. The patient was not keen to face the high risk of faecal incontinence associated with a colo-anal anastomosis.

The TaTME operation proceeded uneventfully. At the time of the surgery the appendix appeared smoothly enlarged and was abnormal in appearance. An appendicectomy was performed. The pathology specimen reported a large polypoid tumour mass, $100 \mathrm{~mm}$ wide and $65 \mathrm{~mm}$ long protruding out of its distal resection margin to a distance of up to $10 \mathrm{~mm}$ beyond its wall. Within the polyp, there was a $20 \mathrm{~mm}$, moderately differentiated adenocarcinoma, with high grade dysplasia. The final staging was T2NOM0, with the appendix reported as a low-grade mucinous neoplasm (LAMN), lined by a mostly flat mucinous epithelium with low grade dysplasia. The neoplasm was confined to the appendiceal wall with no extra-appendiceal cellular or acellular mucin and no invasive malignancy (R0). The decision of the colorectal MDT was to offer a standard post colorectal cancer surveillance. Three months later, staging Computed Tomography scans of the chest, abdomen and pelvis were performed, revealing a $16 \mathrm{~mm}$ lymph node located in the external iliac chain which was considered abnormal. The accepted short axis diameter upper size limit is less than one centimetre for oval nodes and less than 0.8 centimetres for round nodes (7). A subsequent Positron Emission Tomography scan revealed that this node was fluorodeoxyglucose (FDG)avid. Biopsy analysis through fine needle aspiration was inconclusive and the patient went on to undergo a right groin exploration and lymph node dissection. Histopathological analysis of this tissue, using standard staining with haematoxylin and eosin, demonstrated reactive lymphoid tissue only with no malignant changes seen. 
Table I. Reported cases in the literature.

\begin{tabular}{|c|c|c|c|c|c|c|c|c|}
\hline Author & Year & Cancer & Operation & Gender & $\begin{array}{l}\text { Age at } \\
\text { original } \\
\text { surgery }\end{array}$ & $\begin{array}{c}\text { Age at } \\
\text { diagnosis } \\
\text { of recurrence } \\
\text { at colostomy site }\end{array}$ & $\begin{array}{c}\text { Interval } \\
\text { (years) }\end{array}$ & $\begin{array}{c}\text { Original } \\
\text { staging }\end{array}$ \\
\hline Takami et al. & 1983 & Rectal & APR & M & 19 & 38 & 19 & Not stated \\
\hline Saegusa & 1986 & Rectal & APR & M & 55 & 60 & 5 & Not available \\
\hline Nakano et al. & 1987 & Rectal & APR & $\mathrm{F}$ & 31 & 53 & 22 & Not available \\
\hline Takeyuchi et al. & 1990 & Rectal & APR & M & 44 & 56 & 12 & Not available \\
\hline Ohta et al. & 1991 & Rectal & APR & $\mathrm{F}$ & 68 & 77 & 9 & Not available \\
\hline Ishikawa et al. & 1994 & Rectal & APR & $\mathrm{F}$ & 46 & 76 & 30 & Not available \\
\hline Ohtsuka et al. & 1996 & Rectal & APR & M & 77 & 81 & 4 & Not available \\
\hline Shibuya et al. & 1997 & Rectal & APR & M & 73 & 81 & 8 & Duke's A \\
\hline Mechet-Boillot et al. & 2000 & Rectosigmoid & Hartmans & $\mathrm{F}$ & 76 & 78 & 2 & Not available \\
\hline Mechet-Boillet et al. & 2000 & Rectal & AR & F & 85 & 87 & 2 & Not available \\
\hline Townley et al. & 2005 & Rectal & APR & $\mathrm{F}$ & 52 & 57 & 5 & Duke's A \\
\hline Chintamani et al. & 2006 & Rectal & APR & M & 30 & 36 & 6 & T4 N0 M0 \\
\hline Greenberg et al. & 2006 & Rectal & APR & $\mathrm{F}$ & 44 & 44 & 0.5 & T2 N0 M0 \\
\hline Vijayasekar et al. & 2008 & Rectal & APR & $\mathrm{F}$ & 47 & 61 & 14 & T4 N0 M0 \\
\hline Varma & 2011 & Rectal & $\mathrm{AR}$ & M & 34 & 51 & 17 & Not available \\
\hline Kuo et al. & 2012 & Rectal & LAR & $\mathrm{F}$ & 71 & 71 & 0.5 & T4 N1 M0 \\
\hline Cremades-Pérez et al. & 2015 & Rectal & APR & $\mathrm{F}$ & 31 & 58 & 27 & Not available \\
\hline Sarma et al. & 2015 & Sigmoid & Hartmans & $\mathrm{F}$ & 72 & 74 & 2 & Not available \\
\hline Davey and McCarthy & 2020 & Rectal & TaTME & $\mathrm{F}$ & 59 & 61 & 2 & T2 N0 M0 \\
\hline
\end{tabular}

APR: Abdominoperineal resection; AR: anterior resection; LAR: low anterior resection; TaTME: trans-anal total mesorectal excision.

Table II. Secondary outcomes and treatment undertaken.

\begin{tabular}{|c|c|c|c|c|}
\hline Author & Year & $\begin{array}{l}\text { Original } \\
\text { Staging }\end{array}$ & $\begin{array}{l}\text { Overall Survival } \\
\text { (after stomal recurrence) }\end{array}$ & Treatment offered \\
\hline Takami et al. & 1983 & Not stated & 2 years (alive) & 1. En bloc resection of colostomy and $5 \mathrm{~cm}$ of distal bowel \\
\hline Saegusa & 1986 & Not available & Not available & Not available \\
\hline Nakano et al. & 1987 & Not available & Not available & Not available \\
\hline Takeyuchi et al. & 1987 & Not available & Not available & Not available \\
\hline Ohta et al. & 1991 & Not available & Not available & Not available \\
\hline Ishikawa et al. & 1994 & Not available & Not available & Not available \\
\hline Ohtsuka et al. & 1996 & Not available & Not available & Not available \\
\hline Shibuya et al. & 1997 & Duke's A & Not available & Not available \\
\hline Mechet-Boillot et al. & 2000 & Not available & 3 years (alive) & 1. Resection and revision of stoma with adjacent colon \\
\hline Mechet-Boillet et al. & 2000 & Not available & $\begin{array}{c}7 \text { years (died - unrelated } \\
\quad-\text { at age } 94 \text { ) }\end{array}$ & 1. Resection and revision of stoma with adjacent colon \\
\hline Townley et al. & 2005 & Duke's A & $\begin{array}{l}6 \text { months } \\
\text { (alive at time of report) }\end{array}$ & 1. Resection and revision of original colostomy \\
\hline Chintamani et al. & 2006 & T4 N0 M0 & 4 years $($ died $)$ & $\begin{array}{l}\text { 1. Wide local excision of stoma, with resection of } \\
\text { descending and } 2 / 3 \text { rds transverse colon } \\
\text { 2. Para and pre-aortic lymphadenectomy } \\
\text { 3. } 12 \text { cycles - Levamisole and } 5 \text { Fluorouracil }\end{array}$ \\
\hline Greenberg et al. & 2006 & T2 N0 M0 & $\begin{array}{l}\text { Not clearly stated "months" } \\
\text { (alive at time of report) }\end{array}$ & $\begin{array}{l}\text { 1. Resection and revision of original colostomy } \\
\text { 2. Leucovorin and oxaliplatin for further metastatic disease }\end{array}$ \\
\hline Vijayasekar et al. & 2008 & T4 N0 M0 & $\begin{array}{l}\text { Not clearly stated } \\
\text { (alive at time of report) }\end{array}$ & $\begin{array}{l}\text { 1. En bloc resection of mass and completion colectomy } \\
\text { 2. Patient declined adjuvant chemotherapy }\end{array}$ \\
\hline Varma & 2011 & Not available & Not stated & $\begin{array}{l}\text { 1. Joint colostomy resection with bariatric operation at } \\
\text { the same time }\end{array}$ \\
\hline Kuo et al. & 2012 & T4 N1 M0 & 7 years (alive) & 1. 21 cycles of 5 Fluorouracil \\
\hline Cremades-Pérez et al. & 2015 & Not available & 2 years (alive) & 1. Resection and revision of original colostomy \\
\hline Sarma et al. & 2015 & Not available & Not stated & 1. No details given on treatment plan accepted by patient \\
\hline Davey and McCarthy & 2020 & T2 N0 M0 & 6 months (alive) & 1. Palliative intent radiotherapy -20 Gray in 5 fractions \\
\hline
\end{tabular}




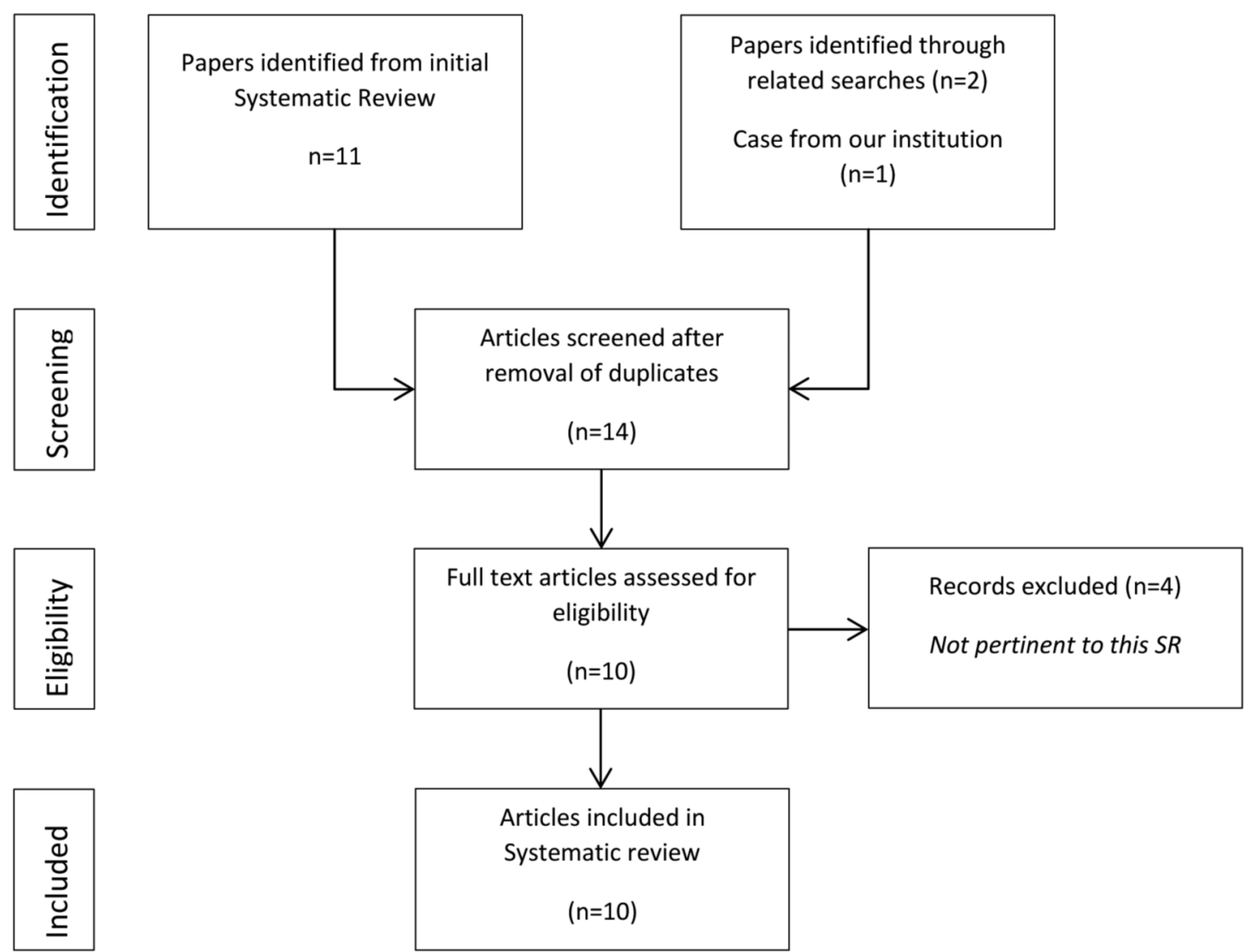

Figure 1. Preferred Reporting Items for Systematic Review and Meta-Analysis (PRISMA) flowchart.

Twenty-one months following TaTME surgery a suspicious mass appeared at the muco-cutaneous junction of the colostomy. It measured $15 \mathrm{~mm}$ and felt woody underneath the skin. Excisional biopsy confirmed a mucinous adenocarcinoma thought to be related to the rectal cancer rather than the appendiceal neoplasm. Staging investigations revealed a $5.6 \mathrm{~cm}$ mass at the site of the end colostomy invading the left rectus muscle. New nodules were felt in the ventral abdominal wall fat, with the largest one measuring 2 $\mathrm{cm}$ at the site of the stoma. Additional peritoneal nodules had formed at the midline. Palliative radiotherapy with 20 Gray in 5 fractions was commenced. Having had a good response to treatment with no regression visible at the stoma, the patient was still alive 6 months later. Additional chemotherapy is still an option, however, at the time of writing serious consideration had to be given concerning concurrent chemoradiotherapy due to the Covid-19 pandemic.

Systematic Review. The literature search returned 11 articles of which 7 abstracts were identified for further review (see Figure 1: PRISMA flowchart). Two papers were identified through a manual search of the "related articles" function in
Pubmed. One further case was added to the dataset from our own institution. We thus identified a total of 9 papers from the systematic review, which, including our case, yielded 19 individual incidences of either metastases or metachronous disease at a stoma site reported since 1983, where the original operation had been undertaken for a rectal or a sigmoid malignancy.

Study characteristics and primary outcome. Our primary outcome was to identify the number of cases of cutaneous stomal recurrence after curative rectal cancer. We identified 19 such cases (Table I). Only one non-English written study was identified, for which a translation was obtained. Of the 19 cases, 7 involved males and 12 involved females, with a median age of 52 years (range $=19-85$ ) at the time of original surgery. The median time from the original operation to recurrence was 6 years (range $=6$ months -30 years). In terms of the location of the cancers, two were labelled as either sigmoid or rectosigmoid, while the remaining 17 were located in the rectum.

Staging was either incompletely reported or not available for 12 of the 19 cases. Cases reported before 2000 used the 
Duke's staging criteria (8), while most of the more recent cases (post 2000) used the current standard tumour, node, metastasis criteria, abbreviated to TNM (9). In cases where the original pathology was reported (see Table I), there were two Duke's A, with two T2 and three T4 cases. Only one case was $\mathrm{N} 1$ at the time of original diagnosis. None had metastatic disease on original presentation.

Of the 19 reported cases, $12(63 \%)$ underwent APR and one $(5.2 \%)$ went through a laparoscopic low anterior resection. Two $(10.5 \%)$ of the anterior resections were not specified further $(24,27)$. A Hartman's procedure was performed in two other cases $(10.5 \%)(24,28)$, while in our institution, the case was treated using TaTME (6).

Without a reported, detailed histology of the new deposit, we cannot clearly state which of these cases represents a true metastasis or a metachronous disease. However, looking at the timeframe from the original operation to the diagnosis of the new deposit, 9 recurrences occurred within 5 years or less, while the remaining ones appeared after 5 years. This may indicate that these 9 cases involved metastases, whereas the remaining ones are more correctly categorised as metachronous disease.

Secondary outcomes. Overall survival (OS) of patients was not available, or not clear for 11 of the 19 reported cases (Table II). Of the identified cases where OS was reported, the median survival was 30 months (range=6-84 months), calculated using the standard formulas within Microsoft Excel.

Table II outlines the treatment modalities used in each case. A combination of surgery and adjuvant chemotherapy or radiotherapy is reported with varying results.

Given the relatively few cases in the literature, no further attempt was made to estimate the prevalence of stomal recurrence. Our systematic review suggests that purely stomal recurrence is rare.

\section{Discussion}

Whilst there is a high volume of published literature surrounding the cutaneous presentation of colorectal adenocarcinoma, only a few cases of metachronous recurrence and even more rare true cases of metastases at the stoma site have been reported. This systematic review identified a total of 19 cases, out of which only four can be considered as confirmed metastases with five more cases likely to represent metastases. The remaining 11 cases should be considered metachronous disease.

One might argue that the distinction may not seem relevant. However, as discussed further below, categorisation is of vital importance since the emergence of increasing numbers of early recurrence at the stoma site in the literature may indicate that we should re-examine our surgical techniques. Five of the nine cases representing likely metastatic recurrence have occurred since 2005. The reasons for this are currently unclear and may simply reflect greater reporting of such cases in the literature.

At present, there is no consensus as to why stomal recurrence occurs. There is an association with local recurrence and distance metastases (10); however, in the 19 cases identified in this systematic review, no patient was noted to have distant metastases at the time of reoperation. Aside from the established and well-understood patterns of spread in colorectal cancer through lymphatics, haematogenous or direct extension (11), there is clearly a concern that iatrogenic implantation or exfoliation of cancer cells during tissue manipulation in the operation is a possible route for metastatic spread (12). The concern regarding implantation has also been considered for the removal of synchronous polyps at colonoscopy. However there is little evidence thus far to support implantation of malignant cells into the colon by removing multiple polyps (13). Another school of thought is that the spread may arise from micrometastasis left behind in the lymph nodes along the inferior mesenteric artery pedicle at the time of the APR. In our case, from initial presentation, there was concern that the patient may have micro-metastases within the external iliac chain; however, we were unable to formally diagnose micrometastatic disease using standard approaches to aspirate and biopsy the nodal chain.

The case we presented here from our institution using the TaTME approach is concerning as there have been other, unusual patterns of recurrence using this approach (14). Previously reported cases have been characterised by rapid, multifocal growth in the pelvic cavity and sidewalls. Norway called a moratorium on the TaTME platform for excision of rectal cancers in 2018 (14), precisely due to the rising concern over these new patterns of recurrence. It should be noted that these concerns surrounding the oncological safety on the TaTME platform are not universally agreed upon (15). Evidence is currently lacking, but the TaTME technique using gas insufflation into the anus in order to facilitate the trans-anal dissection (6), may be part of the explanation as to why these unusual patterns of recurrence have been seen using this relatively new surgical approach. The colorectal community will need to watch closely for the long-term outcomes from this technique.

There is also no reported literature or studies on whether cleaning the stoma using either Betadine or Tisept, prior to bringing it through the abdominal wall, reduces the risk of cutaneous recurrence.

In the papers reviewed, there is little consensus on how to best treat these recurrences. In general, the outcomes are poor since a cutaneous recurrence suggests underlying, disseminated disease. Reports of stomal recurrence prior to 2008 suggest that the median survival after the appearance of 
a cutaneous metastatic lesion is between 18 to 20 months (16) with a range from 1 to 34 months (17). However, in this systematic review, which includes more recently reported cases, the median survival is 30 months with a range from 6 to 84 months. It is important to note that in the cases identified for this review, no other sites of metastatic disease or cutaneous disease had been observed prior to the reoperation or instigation of adjuvant therapy. Our systematic review does suggest that if a metastatic deposit is identified at the stoma site, a sensible discussion about redo surgery with a willing patient is a viable option. Interestingly, where involved inguinal lymph nodes are still present after neoadjuvant therapy, separate surgical excision of such nodes, in addition to the resection of the primary tumour, appears to confer a survival benefit (18). This may suggest that when isolated disease recurrence is present, as in our systematic review, curative surgery is an achievable outcome.

Unfortunately, long-term survival when presenting with cutaneous recurrence is rare. Current treatment options involve wide local excisions plus resiting of a stoma, as well as use of adjuvant therapy. When disease is widespread throughout the pelvis, exenteration is an option with reasonable reported outcomes, preferably in a high-volume centre (19). Currently, there is no consensus from the reported cases regarding the best adjuvant protocol for the rare cases of isolated stomal recurrence. Vijayasekar et al. (17) have reported that their patients are offered chemotherapy under the established FOLFOX and FOLFIRI protocols $(20,21)$; however, patients have turned them down. Sarma and Alvi have stated that their patient was offered palliative chemotherapy with radiation, but no further comment or analysis was made (28). Interestingly, Kuo et al. (22) offered their patient 5-fluorouracil bi-weekly for 21 weeks and the patient was still alive 7 years later. In our own case, the patient received targeted radiotherapy with palliative intent at a dose of 20 Gray in 5 fractions, and is still alive 6 months later. The option of chemotherapy at a later date has not been excluded at this point.

Stomal metastases or metachronous colorectal cancer is uncommon, but they do occur. This systematic review has demonstrated that from the 19 cases we could access worldwide to date, 9 could be interpreted as true metastatic disease.

The cause for this particular pattern of spread is not clear, but given that more cases have been reported in recent years, all units undertaking colorectal resections with newer technology may need to be mindful of this route of spread.

Survival from cutaneous recurrence is generally poor with little understanding of the best way to manage these cases. However, for carefully selected patients, redo surgery can certainly be an option with satisfactory results. For patients with uncertain abdominal lymphadenopathy at the time of rectal cancer diagnosis, we would recommend referral to a specialist centre to consider advanced lymphadenectomy.

\section{Conflicts of Interest}

The Authors declare no conflicts of interest.

\section{Authors' Contributions}

SRD undertook the initial searches and prepared the first draft of the manuscript. KMC was significantly involved in the revisions of the manuscript. Both Authors were involved in the preparation and finalisation of the manuscript to be eligible for authorship.

\section{References}

1 Rawla P, Sunkara T and Barsouk A: Epidemiology of colorectal cancer: incidence, mortality, survival and risk factors. Prz Gastroenterol 14(2): 89-103, 2019. PMID: 3166522. DOI: $10.5114 /$ pg.2018.81072

2 Moran B, Holm T, Brannagan G, Chave H, Quirke P, West N, Brown G, Glynne-Jones R, Sebag-Montefiore D, Cunningham C, Janjua A, Battersby N, Crane S and McMeeking A: The English Low Rectal Cancer Development Programme: key messages and future perspectives. Colorectal Dis 16(3): 173-178, 2014. PMID: 24267315. DOI: $10.1111 /$ codi.12501

3 Perry W and Connaughton J: Abdominoperineal resection; How is it done and what are the results? Clin Colon Rectal Surg 20(3): 213-220, 2007. PMID: 20011202. DOI: 10.1055/s-2007-984865

4 Kim N, Kim M and Al-Asari S: Update and debate issues in surgical treatment of middle and low rectal cancer. J Korean Soc Coloproctol 28(5): 230-240, 2012. PMID: 23185702. DOI: $10.3393 / \mathrm{jksc} .2012 .28 .5 .230$

5 Tan K, Ho K, Lai J, Lim J, Ooi B, Tang C and Eu K: Cutaneous and subcutaneous metastases of adenocarcinoma of the colon and rectum. Ann Acad Med Singapore 35(8): 585-587, 2006. PMID: 17006588.

6 Arroyave MC, DeLacy FB and Lacy AM: Transanal total mesorectal excision (TaTME) for rectal cancer: Step by step description of the surgical technique for a two-teams approach. Eur J Surg Oncol 43(2): 502-505, 2017. PMID: 27914773. DOI: $10.1016 /$ j.ejso.2016.10.024

7 Torabi M, Aquino SL and Harisinghani MG: Current concepts in lymph node imaging. J Nucl Med 45(9): 1509-1518, 2004. PMID: 15347718 .

8 Jass JR and Morson BC: Reporting colorectal cancer. J Clin Pathol 40(9): 1016-1023, 1987. PMID: 3312296. DOI: 10.1136/ jcp.40.9.1016

9 Amin MB, Greene FL, Edge SB, Compton CC, Gershenwald JE, Robert K. Brookland RK, Meyer L, Gress DM, Byrd DR and Winchester DP: The Eighth Edition AJCC Cancer Staging Manual: Continuing to build a bridge from a population-based to a more "personalized" approach to cancer staging. CA Cancer J Clin 67(2): 93-99, 2017. PMID: 28094848. DOI: 10.3322/caac.21388

10 Junginger T, Goenner U, Trinh T, Heintz A, Lollert A, Blettner M and Wollschlaeger D: The link between local recurrence and distant metastases in patients with rectal cancer. Anticancer Res 39(6): 30793088, 2019. PMID: 31177152. DOI: 10.21873/anticanres.13443

11 Wong SY and Hynes RO: Lymphatic or hematogenous dissemination: how does a metastatic tumor cell decide? Cell Cycle 5(8): 812-817, 2006. PMID: 16627996. DOI:10.4161/ cc.5.8.2646 
12 Yamaguchi K, Takagi Y, Aoki S, Futamura M and Saji S: Significant detection of circulating cancer cells in the blood by reverse transcriptase-polymerase chain reaction during colorectal cancer resection. Ann Surg 232(1): 58-65, 2000. PMID: 10862196. DOI:10.1097/00000658-200007000-00009

13 Tan W, Ng N, Chen Y, Chee Y, Foo F, Tang C and Chew M: Synchronous polypectomy during endoscopic diagnosis of colorectal cancer - is the risk of tumour implantation at the polypectomy site significant? BMC Gastroenterol 18(1): 133, 2018. PMID: 30157767. DOI: 10.1186/s12876-018-0861-4

14 Larsen S, Pfeffer F and Kørner H on behalf of the Norwegian Colorectal Cancer Group: Norwegian moratorium on transanal total mesorectal excision. Br J Surg 106(9): 1120-1121, 2019. PMID: 31304578. DOI: 10.1002/bjs.11287

15 Roodbeen S, Spinelli A, Bemelman W, Di Candido F, Cardepont M, Denost Q, D’Hoore A, Houoben B, Knol J, Martín-Pérez B, Rullier E, Sands D, Setton I, Van de Steen K, Tanis P, Wexner $\mathrm{S}$, Hompes $\mathrm{R}$ and Wolthuis A: Local recurrence after transanal total mesorectal excision for rectal cancer: A multicenter cohort study. Ann Surg, 2020. PMID: 31972648. DOI: 10.1097/SLA. 0000000000003757

16 Sarid D, Wigler N, Gutkin Z, Merimsky O, Leider-Trejo L and Ron I: Cutaneous and subcutaneous metastases of rectal cancer. Int J ClinOncol 9(3): 202-205, 2004. PMID: 15221607. DOI: $10.1007 / \mathrm{s} 10147-004-0389-1$

17 Vijayasekar C, Noormohamed S and Cheetham M: Late recurrence of large peri-stomal metastasis following abdominoperineal resection of rectal cancer. World J Surg Oncol 5(6): 96, 2008. PMID: 18771600. DOI: 10.1186/1477-7819-6-96

18 Ueta K, Matsuda T, Yamashita K, Hasegawa H, Mukohyama J, Yamamoto M, Matsuda Y, Kanaji S, Oshikiri T, Nakamura T, Suzuki S and Kakeji Y: Treatment strategy for rectal cancer patients with inguinal lymph node metastasis. Anticancer Res 39(10): 5767-5772, 2019. PMID: 31570480. DOI: $10.21873 /$ anticanres.13779

19 Bacalbasa N, Balescu I, Vilcu M, Neacsu A, Dima S, Croitoru A and Brezean I: Pelvic exenteration for locally advanced and relapsed pelvic malignancies - an analysis of 100 cases. In Vivo 33(6): 2205-2210, 2019. PMID: 31662557. DOI: 10.21873/ invivo. 11723

20 Andre T, Boni C, Mounedji-Boudiaf L, Navarro M, Tabernero J, Hickish T, Topham C, Zaninelli M, Clingan P, Bridgewater J, Tabah-Fisch I, de Gramont A, Multicenter International Study of Oxaliplatin/5-Fluorouracil/Leucovorin in the Adjuvant Treatment of Colon Cancer (MOSAIC) Investigators: Oxaliplatin, fluorouracil, and leucovorin as adjuvant treatment for colon cancer. N Eng1 J Med 350(23): 2343-2351, 2004. PMID: 15175436. DOI: 10.1056/NEJMoa032709
21 Rougier P, Van Cutsem E, Bajetta E, Niederle N, Possinger K, Labianca R, Navarro M, Morant R, Bleiberg H, Wils J, Awad L, Herait $\mathrm{P}$ and Jacques $\mathrm{C}$ : Randomised trial of irinotecan versus fluorouracil by continuous infusion after fluorouracil failure in patients with metastatic colorectal cancer. Lancet 352(9138): 1407-1412, 1998. PMID: 9807986. DOI:10.1016/S01406736(98)03085-2

22 Kuo Y, Chin C and Lee K: Metastasis at the colostomy site: A rare case report. Jpn J Clin Oncol 42(8): 753-756, 2012. PMID: 22641645. DOI: $10.1093 /$ jjco/hys081

23 Takami M, Hanada M, Kimura M, Takeuchi N and Takada T: Adenocarcinoma arising at a colostomy site. Report of a case. Dis Colon Rectum 26(1): 50-52, 1983. PMID: 6822162. DOI: $10.1007 / \mathrm{bf02554682}$

24 Mechet-Boillot I, Chakthoura G, Berard P: Récidive stomiale d'un adénocarcinome rectal. Résection-transposition de las colostomie sans laparotomie. Ann Chir 125(5): 489-490, 2000. PMID: 10925495. DOI: 10.1016/s0003-3944(00)00227-3

25 Townley W, Kothari M and Meyrick-Thomas J: Metachronous stomal adenocarcinoma following abdominoperineal resection for rectal cancer. Ann R Coll Surg Eng 87(6): e1-e3, 2005. PMID: 16263022. DOI: 10.1308/147870805x60798

26 Chintamani, Singhal V, Bansal A, Bhatnagar D and Saxena S: Isolated colostomy site recurrence in rectal cancer - two cases with a review of the literature. World J Surg Oncol 13(5): 52, 2007. PMID: 17567928. DOI: 10.1186/1477-7819-5-52

27 Varma S: Second primary peristomal carcinoma: a case study. Br J Nurs 20(16): S23-24, S26, 2011. PMID: 22096805. DOI: 10.12968/bjon.2011.20.sup9.S23

28 Sarma D and Alvi A: Stomal metastasis of colorectal cancer. Br J Hosp Med (Lond) 76(11): 665, 2015. PMID: 26551500. DOI: 10.12968/hmed.2015.76.11.665

29 Cremades-Pérez M, Gómez-Artacho M, Navinés J and Fernández-Llamazares-Rodrigues J: Adenocarcinoma at the site of a terminal colostomy. A rare but important entitiy. Rev Esp Enferm Dig 107(5): 309, 2015. PMID: 25952806. DOI: 11300108/2015/107/5/309 